\title{
Emerging Knowledge Networks as a Background For Educational Management
} Learning from Information Industries

\author{
Mikko J. Ruohonen \\ Department of Computer Sciences, FI-33014 University of Tampere, Finland \\ mr@cs.uto.fi
}

Abstract: Knowledge-based organisations are facing constant changes in their operations and management models. Industry structures are converging which means new business processes and organizational structures. Hence, interorganisational competitive advantage demands cross-organisational learning and management. Knowledge workers need to create new competencies and management processes need to be contextualized. Knowledge work characteristics are applied in the context of the information and communications technology (ICT) industry. Finally an explorative framework for knowledge work leadership is developed and tentative empirical guidelines are reviewed.

Key words: Knowledge work, ICT industry, inter-organisational competitive advantage, organisational contexts, management approaches.

\section{TRANSFORMATION OF THE ICT INDUSTRY}

The use of information and communications technology (ICT) has emerged as an important target of management. In addition to improving cost-effectiveness, it also offers great potential for innovations (Ruohonen \& Salmela 1999). E-business is starting a change process in which organisations must think about operations models, organisational processes, and ways to meet and serve customers needs (Kalakota \& Robinson 2001).

Functional hierarchies have turned to be more organised networked structures. The functional growth of a company is often based on buying competing companies, mergers, or branch rationalisation to make strategic 
alliances. Mass production has turned into a customer-oriented operation and even mass-customised (Pine \& Gilmore 1997, Contractor \& Lorange 2002). Different collaboration and outsourcing strategies will become more important (Kern \& Willcocks 2002). Collaboration is not just based on transferring transactions between companies, it is also sharing knowledge, uniting and integrating processes and developing joint measures for operations. We call it an era of knowledge management networks (Ruohonen \& Salmela 1999, Warkentin et al. 2001).

The information production and services industry, later information industries, is one of the drivers and enablers of the aforementioned change. Different products and services of the companies which handle information technology, telecommunications, digital contents industry and related fields provide opportunities for new innovations. It means that a strong commitment and ability to network reliably with their partner organisations should exist. The management of co-operation between organisations becomes a key factor in this challenge. Formal agreements between organisations are just a start - the building of knowledge networks demand new qualities both from organisations and their managers. The next four qualities (Dyer \& Singh 1998) are important as the source of the competitive advantage between the organisations:

- Relation-spesific assets i.e. investing in the specific relationship of partners.

- Knowledge-sharing routines between partners.

- Complementary resources supplementing core competencies of each partner.

- Effective governance of the relationship.

The knowledge creating companies should manage of all these qualities. This is also the case when organizing your educational management services, for example, when the organisation either co-operates within an ICT development project or has a constant outsourcing service relationship with a customer company. This is reflected, among others ways, in the administration and maintenance of electronic exchanges, in the management of communication network services or in the fostering the use of intranets. 


\section{MANAGEMENT OF INTERORGANISATIONAL COMPETITIVE ADVANTAGE}

\subsection{Relation-Specific Assets}

The co-operative relationship between organisations is not merely by control of formal agreements, as the organisations must also bind themselves into the long-term cooperation. Starting of outsourcing services begins the co-operation relationship with many options to change this relationship. Pricing, cost control and exit provisions just provide a skeleton for a tighter co-operative relationship. It must be possible to evaluate the outsourcing operations and at the same time be possible to make selective outsourcing possible. The outsourcing which produces added value leads to changing of the models and the co-operation relationship, and the cutting short of costs remains "business-as-usual" (Lacity \& Hirscheim 1993, McFarlan \& Nolan 1995). The service provider must be able to learn the organisational model and processes of customer organisations. At the same time customer organisations have to be ready to become acquainted with the products and service alternatives beyond the approach of traditional transaction costs. The professionals' working in the service organisation must be in line with customer responses. The service organisation should take care of the customer's schedules and timetables. Both parties must accept that when building co-operation, one must commit oneself to invest in that relationship continuously, both economically and mentally. Very few co-operative projects start moving without incidents and succeed by a first attempt. The success of the co-operation is strengthened especially by mutual trust which is claimed to be a necessary condition to the genuine co-operation project.

\subsection{Knowledge-Sharing Routines Between Partners}

Currently many organisations organise their information systems services behind common web-based portals. This takes place, for example, in the public administrative and educational services, supply of the tourism industry, procurement of the car industry, paper, metal and electronics industries. Unfortunately these exchanges or portals tend to be only cybercrossings. Hence, the customer arrives at this crossing from which he chooses the following direction and never returns. The exchange of knowledge should be two-directional in knowledge networks. Stakeholders must learn from each other for improved service of customers and better competitiveness. If the holder of the portal considers the meeting place only 
as the strengthening of his own position on the market, the portal becomes rather a bulletin board which is full of ads. However, if the portal is designed to be a problem-solving space it requires community knowledge sharing practice of the portal partners. The transfer of customer knowledge, for example, to competitors, is extremely difficult because knowledge interrelates to context. Many organisations, such as Avnet/Marshall, have operated within the field and developed their services continuously for a long time towards proactiveness, right pricing of services and anticipation of customer needs (El Sawy et al. 1999, Turban et al. 2002). So the added value is not based on control of the transaction cost, it is searched beyond control of the traditional value chain (Stabell \& Fjeldstad 1998).

\subsection{Complementary Resources or Capabilities}

The resource-based theory from the firm (Barney 1991) calls for those resources which are valuable, rare, hard to copy and effectively organised from the point of view of the competition. The core competence has often been created in time, self-steered and even by chance. It is particularly difficult for management to see the importance of competencies created at the floor level. The learning created in action and while facing customers provides a foundation for success. However, these competencies can become obsolete if competitive or technological changes affect our business environment. The competitive advantage of knowledge networks is created through a clustering process in which two or more organisations with complementary competencies begin to compete against other competitors' clusters with similar interests. This creates a match-making and grouping process. First the exchange of knowledge will be clustered around different technology options but at the following stage one already must think what kind of customer groups we are taking care of. The complementary competencies can open new markets and technology areas. Traditionally we avoid situations in which espionage or stealing of corporate core competencies is obvious. On the other hand, there are viewpoints according to which external competencies should be produced in the hyper-competitive businesses (D'Aveni 1995, Matusik \& Hill 1998).) Japanese car manufacturers are able to distribute knowledge inside a trusted network while in the US business environment formal agreements and sanctions dominate business (Dyer and Singh 1998).

\subsection{Effective Governance of the Relationship}

Competitive advantage is not achieved if costs of cooperation exceed the level of other similar ones by competitors. So a project, such as the service 
portal, must be governed effectively, for both the technical infrastructure and the contents (i.e. services). Co-operation rules of practice must be created while different stakeholder groups control their own interests. It is good to have a mediating organisation - an official broker which functions formally or based on partner relationships. The ways of action have pointed to persons in charge of organisations and the processes must be clear and explicit to every partner. The broker must be able to operate fast without constantly arranging meetings when cooperation proceeds and the customer interface changes. Situations in which this customer setting has to be evaluated and checked will be created continuously.

\section{A FRAMEWORK FOR KNOWLEDGE WORK LEADERSHIP}

\subsection{Contextual Approaches Needed}

The ICT industry has been stamped by a strong turnover. The knowledge workers have looked for more inviting jobs for themselves and for new possibilities opening in the field. The motivation base is, or at least has been, mainly economical. Companies have had to persuade the experts of the new economy by better salaries and share options. A number of ICT companies have experienced the first phase of the knowledge company lifespan. In this phase nearly any way of working went through and customers were willing to pay for that. This was very evident in late 1990s in the so-called dotcomcompanies. Search for "the new economy experts" ended up with acceptance of poor quality management and productivity guidelines. Project management and business know-how was not really appreciated while it was more interesting to strive for Initial Public Offerings and sky-rocketing rise of shareholder value. Most of the companies were very small in size, with no business management experience and personnel of very young age and narrow qualifications. Hence, there was no clear management practice. The companies were more like bunches of good friends or families. However, now ICT companies also try to create other attraction factors than economic advantage. The economic advantages are a kind of hygienic factors as such but in addition to them the sensibility of the work and ways of action, the character of the work community, the culture of the organisation and management style and the general attractiveness of the business branch are evaluated. Knowledge management is also the evaluation of your company management approaches, not just technology. The new start-up companies 
enjoy the advantage of quick implementation of new practices. Those organisations with a longer time in business have probably created different organisational rules which are slow to change. More experience and knowledge is needed concerning management practices in different information industry contexts (Ruohonen et al. 2003).

\subsection{The Explorative Framework}

The following generic framework is an exploration of the empirical findings from case companies (Ruohonen et al. 2003). The framework is proposed to be continuously evaluated against empirical findings and elaborated to a more advanced description. The dimensions for categorizing different contextual knowledge work management approaches are defined by external variety (competitive business forces) and internal variety (personnel differences). Competition has put pressure on all information organisations, but especially on those which made a fresh and glorious start (dotcomcompanies). Most of the companies have failed now and faced the rules of competition. Competition makes companies aware of good quality and project deadlines. Personnel differences refer to those emerging challenges which are rising from differences in age, culture, job career, professional backgrounds, even gender and race in some societal contexts.

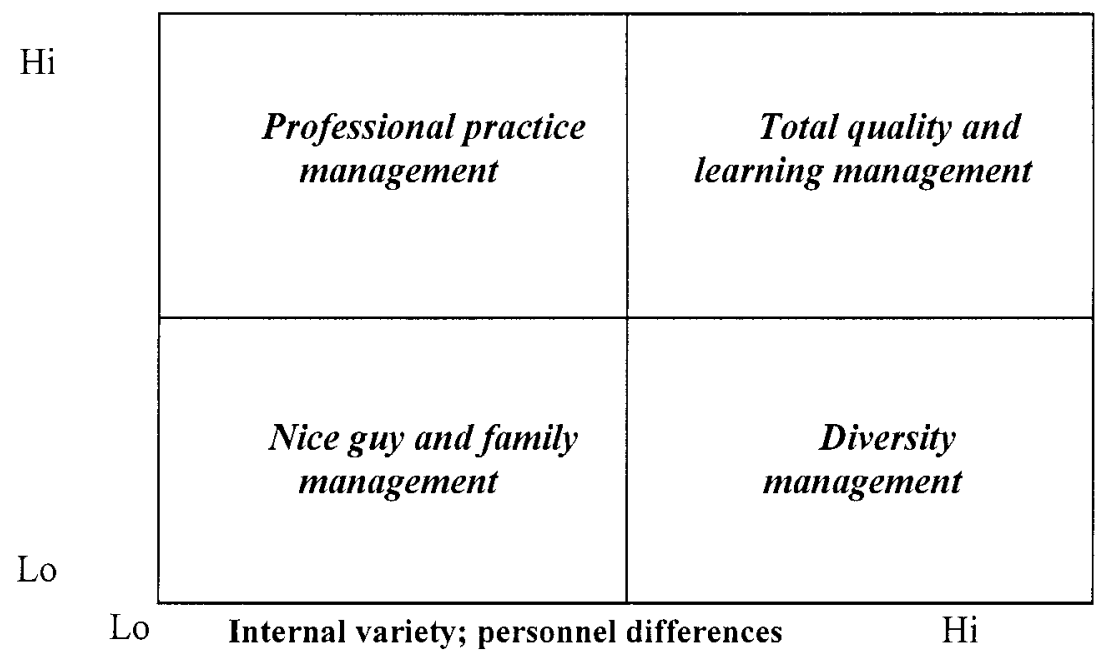

Figure 1. A framework for knowledge work leadership approaches 


\subsubsection{Nice guy and family management}

This corner of the framework represents the typical start-up company. In those companies customer intimacy might be great and knowledge sharing is easy while the company is small in size. All people can participate in joint problem solving and project sessions. However, in these companies recognition of complementary resources is seldom done explicitly. Normally there is a shortage of resources which force buying companies to use these services. Governance of projects, such as e-commerce projects, is normally poor. Quality is low and timetables are flexible. These companies first provide value due to market inequivalencies, but when markets develop and customers learn to demand more, quality management becomes problematic. Management of people is based on "nice guy feelings", normally managerial structures are avoided and there are no systematic administrative processes. Office hours are very flexible and people like to use their freetime with their colleagues or even stay overnight in the office. Management follows the guidelines of how to work with your friends or even family members.

\subsubsection{Diversity management}

This describes the situation which has been typical for some of the growing dotcom companies. They have increased their size by buying smaller companies and in the same time got publicly listed. The rapid growth has created problems of communication and management structures and also clash of cultures. Many small family management companies have been destroyed by these acquisition maneuvers. Interorganisational competitive advantage emerges from the four competitive factors previously described. Relation-specific assets grow but they are fragmented according to certain specialist and competence groups i.e. customers are not really customers of the new merger-based company. Projects are more diverse in nature and demand variety of personnel competencies. Knowledge sharing might grow problematic due to rapid growth and different learning styles of personnel. It is increasingly more difficult to gather complementary resources for a larger customer project. Governance can still be poor, and that affects the quality provided. The challenge is diversity management, both projects and human resources become more diverse and managers need to know more about different psychological, social and cultural phenomena which are reflected in their daily work. 


\subsubsection{Professional practice management}

This corner is the possibility for a rather homogenous personnel in harder competition. If companies can create more systematic approaches, improve their strategies, structures and processes in line with customer demands they might survive. However, this means that some of the workers are not happy while they can not do what they want. Project managers need to be aware of project deadlines, strong enough to resist last minute changes and very authoritative when people are producing over-quality. The advantage of these companies is longer customer relationships which have educated both parties to do their best. Professional rules, patterns and even support systems can help knowledge sharing inside the company and with customers. Complementary competencies are identified and constant review of service quality is executed. Governance is more systematic but enables freedom when necessary. In these companies world-class innovations are possible. Professional practice management develops the company further.

\subsubsection{Total quality and learning management}

This is the most challenging while it requires both the management of business competition but also different diverse personnel management approaches. These companies are normally the big players in the field which provides many branches of services to customer companies. They normally also have very diverse personnel working abroad. These businesses need to take care of both "old" systems and emerging new economy systems. They analyse, support and consult strategy making. Many of these take care of outsourcing and application service provision. They hire people for customer companies. Relation-specific assets are usually managed by account managers who are responsible for certain customer projects. Projects and customers are categorized. They have initiated both formal (IT-based) and informal (face-to-face) knowledge sharing practices with information systems support. Complementary resources are strived through team building, task forces and evolving organisational arrangements. Governance uses total quality management and critical chain reviews. Quality is defined either by excellence criteria or with meeting customer demands. In the same time these companies face a clear threat of becoming too bureaucratic, therefore active learning management processes are needed too. Especially processes which support reflection are needed. Both quality and learning management makes the manager an acrobat on one hand trying to keep costs and schedules, while on the other hand enabling creativity, freedom of ideas and professional learning. 


\section{FINAL REMARKS}

A theoretical framework was reviewed for emerging knowledge work and leadership cultures in the ICT industry. Competition and increasing pressure to make network economy demands new competencies. Interorganisational competitive advantage requires cross-organisational learning and working processes. Knowledge work has to face productivity challenges. Managers need to identify the context they are working in order to align with personnel competences. An explorative framework was provided and described against theoretical groundings and empirical findings of an on-going research project. The framework will be elaborated with further research on emerging knowledge work and management practices.

\section{REFERENCES}

Barney, J.B. (1991) Firm resources and sustained competitive advantage. Journal of Management 17(1), 99-120.

Contractor, F.J. \& Lorange, P. (2002) The growth of alliances in the knowledge-based economy. International Business Review 11, 485-502.

D'Aveni, R. A. (1995): Hypercompetition: Managing the dynamics of strategic maneuvering. New York: Free Press

Dyer, J.H. \& Singh, H. (1998): The relational view: Cooperative strategy and sources of interorganisational competitive advantage. Academy of Management Review 23(4) 660679.

El Sawy, O.A., Malhotra, A., Gosan, S. \& Young K.M. (1999): IT-Intensive Value Innovation in the Electronic Economy: IT-Intensive Value Innovation in the Electronic Economy: First Prize, 1997 SIM International Paper Awards Competition.

Kalakota, R. \& Robinson, M. (2001): E-Business 2.0. Addison Wesley Longman, Reading, Massachusetts.

Kern, T. \& Willcocks, L. (2002) Exploring relationships in information technology outsourcing. European Journal of Information Systems 11,3-19.

Lacity, M.C. \& Hirscheim, R. (1993) Information systems outsourcing myths, metaphors and realities. Wiley, Chichester.

Matusik, S.F., Hill, C.W.L. (1998): The Utilization of Contingent Work, Knowledge Creation, and Competitive Advantage. Academy of Management Review 23(4), 680-697.

McFarlan, F.W. \& Nolan, R.L. (1995) How to Manage an IT Outsourcing Alliance. Sloan Management Review 36(2), 9-23.

Gilmore, J.H. \& Pine, J. II (1997): Four Faces of Mass Customization, Harvard Business Review Jan-Feb 1997, 91-101.

Ruohonen, M. \& Salmela, H. (1999): Yrityksen tietohallinto. Edita, Helsinki.

Ruohonen, M., Kultanen, T., Lahtonen, M., Rytkönen, T. and Kasvio, A. (2003) Identity and Diversity Management for New Human Resource Approaches in the ICT industry. In F. Avallone, H. Sinangil \& A. Caetano (eds) Identity and Diversity in Organisations. Milan: Guerini Studio. 
Stabell, C.B. \& Fjeldstad, Ö, D. (1998) Configuring value for competitive advantage. on chains, shops, and networks. Strategic Management Journal 19, 413-437.

Turban, E., King, D., Lee, J., Warkentin, M. \& Chung, H. (2002) Electronic Commerce - a Managerial Perspective. Prentice Hall.

Warkentin, M., Sugumaran, V. \& Bapna,R. (2001) E-knowledge networks for interorganizational collaborative e-business. Logistics Information Management 14(1/2), 149-162. 